\title{
Reasons for encounter in young people consulting a family doctor in the French speaking part of Switzerland: a cross sectional study
}

\author{
Anne Meynard ${ }^{1 *}$, Barbara Broers ${ }^{2+}$, Danièle Lefebvre ${ }^{3 \dagger}$, Françoise Narring ${ }^{1+}$ and Dagmar M. Haller ${ }^{1,4+}$
}

\begin{abstract}
Background: Knowledge of patient's reasons for encounter is useful to inform health service planning and health professional education. Our aim was to describe reasons for encounter as stated by an unselected group of young people attending primary care practices in the French-speaking part of Switzerland.

Methods: Consecutive patients aged between 15 and 24 years were recruited as part of the PRISM-Ado trial $(n=594)$. They completed an anonymous questionnaire in the waiting room, including their main reason for encounter (free text). Reasons for encounter were coded using ICPC-2 classification and analyzed according to sex, age and living in a rural or urban area.

Results: $95 \%$ of questionnaires contained valid data about reasons for encounter ( $n=567)$. General and unspecific (A) reasons were the most common in boys (44\%) and girls (42\%), followed by respiratory, musculoskeletal, dermatological and psychological reasons. Psychological reasons were more frequent in girls attending urban practices; musculoskeletal and dermatological reasons were more frequent in rural areas. Sexually transmitted infections or substance use were very rarely stated as a reason for encounter.
\end{abstract}

Conclusions: This is the first study describing reasons for encounter as stated by young people themselves in primary care in Switzerland. These findings provide useful guidance for family doctors training and health service planning in Europe.

Trial registration: Australian New Zealand Clinical Trials Registry, ACTRN12608000432314.

Keywords: Young people, ICPC-2, Family medicine, Reason for encounter

\section{Background}

Providing comprehensive care for the general population throughout the life course is the cornerstone of family medicine. Recent research emphasizes the importance of a lifecourse approach in adolescent health [1]. This includes for example addressing health compromising behaviours that usually start in adolescence and affect later life, ensuring immunization coverage, or encouraging a responsible use of health services. Family medicine represents the main point of access to care for young people in the world. In Switzerland as in other high

\footnotetext{
* Correspondence: anne.meynard@hcuge.ch

${ }^{\dagger}$ Equal contributors

'Adolescent and young adult program, Department of Child and Adolescent Health, Geneva University Hospitals, 87 Bvd de la Cluse, 1205 Geneva,

Switzerland

Full list of author information is available at the end of the article
}

income countries, most young people use primary care at least once a year with no differences between young people engaging in health compromising behaviours or not $[2,3]$.

Although adolescence is often seen as a period of opportunities and good health, the burden of disease in adolescents and young adults (10-24 years) is far from negligible. In all regions of the world there is an excess mortality in 15-24 year old boys mainly related to violent deaths (traffic accidents, violence and suicide). Girls' mortality worldwide is still related to maternofetal causes but in high income countries suicide and accidents are also the main cause of mortality in this age group [4]. In high income countries like Switzerland, mortality remains low but burden of disease as measured by DALY's (disability adjusted life years) significantly rises 
from early to late adolescence especially around mental health, substance use but also iron deficiency and consequences of unsafe sex [5]. Evidence shows that public health campaigns and school health programs focusing on development of healthy environments and life skills among young people are effective [6].

Gaining a better understanding of young people's reasons for encounter can help adapt training programs and sensitize family doctors to young people's health needs. Primary care providers can reinforce public health messages at the individual level and encourage responsible use of health services with adolescents as they are their future adult patients. If adequately trained they can well respond to the needs of adolescents $[7,8]$.

The International Classification for Primary Care-2 (ICPC-2) is internationally recognized as the best tool for coding primary care medical encounters. The Swiss Society for General Medicine has therefore acknowledged ICPC as the official coding system for primary care and recently developed a project for better coding in primary care (FIRE project) [9-11]. FIRE provides a view of reasons for encounter from a doctors' perspective and not from a patient's point of view .It does not provide data on children or young people.

We reviewed three studies addressing self-reported health needs of young people in relation with family medicine, all of them using ICPC coding. In an Australian study describing the profile of $16-24$ year old young people consulting a family doctor, 450 young people were interviewed confidentially and their reasons for encounter coded using ICPC-2 [12]. In Europe two studies focused on young people's ICPC coded reasons for encounter. One was a German study (0-19 years old) the aim of which was to describe access to family medicine of children and adolescents aged 0-19 years old [13]. The other study was a Franco-Belgian study comparing reasons for encounter as reported by young people (12 to 17 years old) and those reported by family doctors for these same young people [14]. In all studies young people's most frequent reasons for encounter with a family doctor were respiratory, general, musculoskeletal and skin reasons with some differences especially gynecological reasons being more frequent in the Australian study and very low in all the others. Substance use and mental health issues as well as injuries were rarely mentioned.

The rationale for our study was to focus on the period of transition between adolescence and young adulthood based on the World Health Organization definition of adolescence (10-24 years old). We were also interested to collect data on older adolescents and young adults as epidemiological data shows a rising burden of disease in these age groups.
To date, there are no published studies in Switzerland about young people's utilization of primary care facilities: differences between urban and non-urban or geographical areas or reasons for encounter as described by young people themselves. The aim of our study was to describe young people's stated reasons for encounter in private family medicine practices in Switzerland.

\section{Methods}

\section{Study design and setting}

This is a cross-sectional study conducted in family medicine practices (general internists and paediatricians) in the French-speaking part of Switzerland. Data were extracted from baseline data of a large primary care cluster randomised controlled trial (PRISM-Ado trial) conducted from February 2009 to November 2010 [15]. The PRISM-Ado trial tested a training intervention of family doctors to address substance use in adolescents.

\section{Swiss context of care}

Switzerland has a universal health coverage system through private insurance schemes. As it is a federal state, every canton has different health regulations. There is easy access to primary care (paediatricians, general practitioners or general internists now all are members of a national association of family medicine). Family doctors do not necessarily act as gate-keepers, patients have free access to specialized care. Pediatricians are part of the primary care system and can follow their patients into young adulthood without restrictions although most paediatricians encourage transition to adult care around the age of 16 .

The Swiss population especially in urban areas also has easy access to outpatient emergency clinics, hospital emergency units. Family planning clinics and gynecologists are the main source of care for sexual and reproductive health care. Recent data from the Swiss Health Observatory show that $60 \%$ of the 15-34 year old see a family doctor at least once a year and $26 \%$ a specialist. These data do not allow more refined analysis (whether they have seen both a family doctor and a specialist for example) [16].

According to cross-sectional population based data (The second Swiss Multicenter Adolescent Survey on Health) [17] three quarter of the adolescents has seen a family doctor at least once in that year, one third had seen a specialist and $50 \%$ of girls had seen a gynecologist.

\section{Participants}

Young people aged 15 to 24 years attending the practices of 32 physicians participating in the PRISM-ADO trial were included [15]. The choice of the age-range 15 to 24 years ("youth" according to the United Nations 
definition) was based on two considerations: young people in this age-group share a similar burden of disease throughout this developmental phase from adolescence into adulthood [18]. In addition, as from the age of 15 years they could participate in this low risk study without asking for parental consent [19]. The Swiss federal law on research states that parental consent is not required in low risk studies for adolescents less than 16 years old [20]. All consecutive patients in this age group attending the practice during the trial period were eligible. Patient exclusion criteria were: acute illness requiring immediate attention of the physician, severe mental disorder such as psychosis or suicidal thoughts, drug or alcohol abuse requiring more immediate attention (i.e. alcohol abuse and recent court ruling regarding drunk driving), previous treatment for cannabis or alcohol dependence, inability to read and understand French, any other disorder affecting the capacity of the young person to consent on their own to participate in the study. Participating practices were not chosen at random: family doctors volunteered to participate in the trial. However the sample was varied with representatives of different age groups and both genders, single, double or group practices, in rural or urban settings (Table 1). Acceptance rate of participation by the patients was high $(594 / 666=89 \%)$, so we can consider our study population as an unselected group of young adults consulting their primary care physician. 32 patients were excluded because of an acute illness, 40 patients denied participation. Details about acute illness leading to exclusion and reasons for refusals were not systematically recorded.

\section{Instruments and procedure}

The practice assistant recruited eligible patients as they came in for their consultation. Prior to the consultation, participants were invited to complete a confidential

Table 1 Characteristics of the 32 participating family doctors

\begin{tabular}{lll}
\hline Characteristics & $N(\%)$ & $\begin{array}{l}\text { National data } \\
2012^{\mathrm{a}}(\%)\end{array}$ \\
\hline $\begin{array}{l}\text { Socio-demographic characteristics } \\
\text { Age group, }\end{array}$ & \\
36 to 45 years old & $15(47)$ & $(19)$ \\
46 to 55 years old & $12(37)$ & $(36)$ \\
$>55$ years old & $5(16)$ & $(44)$ \\
Male & $18(56)$ \\
Professional characteristics & $(70)$ \\
Specialty = paediatrics (as opposed & $5(16)$ \\
to general internal medicine) & \\
Solo or duo practice & $25(78)$ \\
Practice located in urban area & $22(69)$ & NA \\
\hline
\end{tabular}

${ }^{\mathrm{a} T h e}$ Commonwealth Fund, International Health Policy Survey 2012 [22] survey with questions evaluating general health, substance use, socio-demographic and psychosocial variables. They completed the survey in the waiting room, or if this did not provide sufficient privacy, in a separate room. The young people always completed the questionnaire before the medical encounter and were asked for practical reasons (time constraint associated with research in a busy primary care practice) to complete only the main reasons for encounter::

\section{"Finally, thank you for stating with your own words the main reason for you to come today (for example: common cold, school problem, prescription for contraceptives, sadness, ankle sprain,...)?"}

Patients completed it in free text and the investigators then coded these complaints using the International Classification for Primary Care 2 (ICPC-2).

ICPC-2 classification (www.icpc.ch)

The structure of ICPC-2 classification is organized in the following way: 17 main chapters from $\mathrm{A}$ to $\mathrm{Z}$ and for each chapter 7 identical components (eg: symptoms/ complaints, infections, neoplasm, injuries, congenital anomalies, other diagnosis). It also contains a section on procedures (blood test, immunization,...). The investigators were familiar with this classification as they had used it in previous studies [12, 21]. The young people filled in free text before the medical consultation. The questionnaire was then anonymously collected and therefore not seen by the doctor or practice assistant. A research assistant (medical student not involved in the care of the patients) coded all the patients' answers using ICPC-2 codes. Procedural codes were related to the corresponding chapter. Ambiguous answers were discussed and consensus sought with one of the main investigators $(\mathrm{DMH})$ to improve reliability of the coding strategy.

Examples: "I come because I feel down" or "I come because I feel sad" was coded P03 "Sensation of depression"

"I come to get a medical certificate for vocational school" was coded A98 and I come to get an immunization" was coded (code procedures) A44"

\section{Analysis}

Data were entered using Epidata and a descriptive analysis of the ICPC-2 coded reasons for encounter was undertaken using Stata software.

Reasons for encounter were analyzed by frequency of occurrence. Analysis was done by chapter (ICPC-2 list A to $\mathrm{Z}$ ) and by individual reason for encounter and then analyzed by age group, gender as well as by geographical distribution of the practices (urban, if $>15^{\prime} 000$ inhabitants, or non urban areas). Two age groups were 
considered: 15 to 19 and 20 to 24 years old. The association between reasons for encounter and age groups, gender and practice location was examined using multivariate logistic regression adjusting for these variables and clustering within practices.

The PRISM-Ado study protocol was approved by the Ethics Committee for Studies in Outpatient Care, Geneva University Hospitals, Geneva Switzerland (protocol 0828). Ethical approval for the PRISM-Ado trial included approval of baseline data collection and descriptive analysis. The baseline questionnaire, including questions about reasons for encounter was submitted and approved by the ethical committee.

\section{Results}

\section{Sociodemographic data}

594 young people completed the study questionnaire. The mean age was $18.5( \pm 2.6)$ years old, $53 \%$ were female. $55 \%$ of the study population were students, mostly living in urban areas (61\%), more than $80 \%$ were born in Switzerland.

\section{Reasons for encounter}

Of 594 questionnaires completed for the PRISM-Ado trial, 567 (95\%) had an answer to the question of reason for encounter that could be coded. The most frequently cited ICPC-2 chapters were A (general + procedural reasons for encounter all related to chapter A) $43 \%, \mathrm{R}$ (respiratory) $16 \%$ and L (musculoskeletal) $12 \%$.

Sensitive topics such as substance use, sexual and reproductive health motives were almost not expressed by young people as reasons for encounter Fig. 1.

\section{Reasons for encounter according to age, gender and practice location}

Table 2 lists all the reasons for encounter and Table 3 illustrates the top ten reasons for encounter in males and females and according to the location of the practice (urban or non-urban). General check up was the most frequent reason both in males and females (43.2 \% $/ 41.9 \%)$, younger or older age groups and urban or nonurban practices. Immunization represented $7.2 \%$ of reasons stated. Musculoskeletal and respiratory reasons were more frequent among males and in non-urban practices but these differences were not statistically significant. Blood (B) reasons for encounter were significantly more frequent among girls. There were no statistically significant differences between the younger and the older age group for all reasons for encounter. Psychological and digestive symptoms were statistically significantly more frequent, skin complaints statistically significantly less frequent in urban practices.

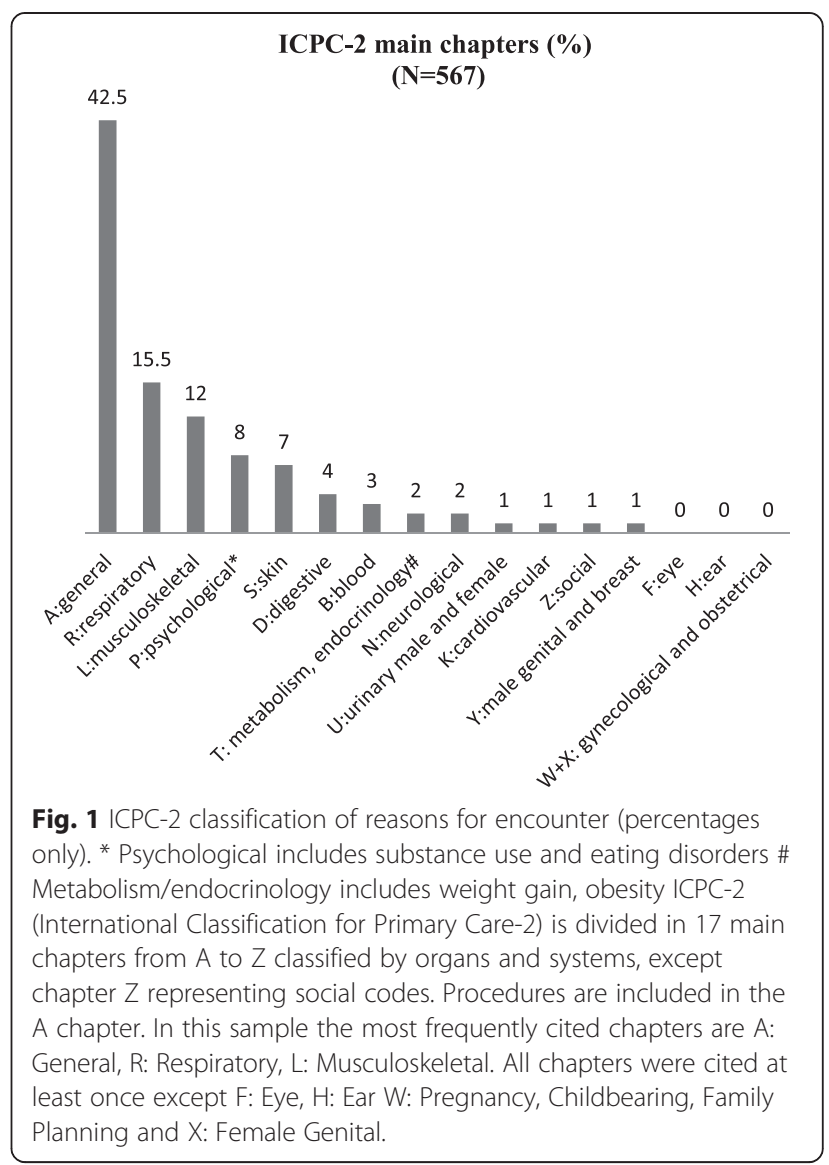

\section{Discussion}

This is the first Swiss study looking at reasons for encounter in primary care for young people.

The most common reasons for encounter cited by participants in this sample are visits for general motives (such as health maintenance or immunization) accounting for more than $40 \%$ of visits with no difference between genders or age groups. Respiratory and musculoskeletal complaints are also frequent in all subgroups. Young people consulting in an urban practice have more psychological and digestive complaints and young people consulting in a non-urban practice have more dermatological and musculoskeletal complaints.

Our results add to the two previous European studies showing data for older adolescents and young adults and from the patient's perspective in another European region. Interestingly our findings are quite comparable to those of the Franco-Belgian study of adolescents aged 12 to 17 years, despite the age difference [12].

As stated earlier, the SMASH survey indicated that $50 \%$ of girls had seen a gynecologist in the current year [17]. We hypothesize that this is still the case in the western region of Switzerland where the study was conducted and thus could explain the low number of 
Table 2 ICPC-2 coded main categories of reasons for consulting as indicated by young people before their consultation and most frequent subcategories (total frequency $>3$ ), by gender, by age-group and by practice location (numbers are percentages)

\begin{tabular}{|c|c|c|c|c|c|c|c|c|}
\hline $\begin{array}{l}\text { Reason for encounter } \\
\text { (main ICPC categories) }\end{array}$ & $\begin{array}{l}\text { Males } \\
(\mathrm{N}=259)\end{array}$ & $\begin{array}{l}\text { Females } \\
(\mathrm{N}=308)\end{array}$ & $\begin{array}{l}15-19 \text { years } \\
(\mathrm{N}=307)\end{array}$ & $\begin{array}{l}20-24 \text { years } \\
(\mathrm{N}=260)\end{array}$ & $\begin{array}{l}\text { Visiting in } \\
\text { urban practice } \\
(\mathrm{N}=353)\end{array}$ & $\begin{array}{l}\text { Visiting in } \\
\text { non-urban } \\
\text { practice } \\
(\mathrm{N}=214)\end{array}$ & $\begin{array}{l}\text { All participants } \\
(\mathrm{N}=267)\end{array}$ & Measures of association ${ }^{a}$ \\
\hline A:general & 43.0 & 41.8 & 43.0 & 41.9 & 44.8 & 38.9 & 42.5 & no significant difference \\
\hline $\begin{array}{l}\text { Health maintenancel } \\
\text { prevention A98 }\end{array}$ & 20.8 & 18.2 & 23.2 & 11.8 & 19.3 & 19.6 & 19.4 & \\
\hline $\begin{array}{l}\text { Preventive -immunisation/ } \\
\text { Medication-44 (A44) }\end{array}$ & 6.9 & 7.5 & 6.6 & 8.6 & 7.9 & 6.1 & 7.2 & \\
\hline $\begin{array}{l}\text { General symptom/ } \\
\text { complaint other A29 }\end{array}$ & 4.6 & 5.5 & 5.5 & 4.3 & 5.4 & 4.7 & 5.1 & \\
\hline $\begin{array}{l}\text { Weakness/tiredness general } \\
\text { A04 }\end{array}$ & 0.4 & 2.9 & 1.6 & 2.1 & 2.3 & 0.9 & 1.8 & \\
\hline Blood test -34(A34) & 1.2 & 1.6 & 1.0 & 2.1 & 2.0 & 0.5 & 1.4 & \\
\hline $\begin{array}{l}\text { Results exam/test/record } \\
\text {-61(A61) }\end{array}$ & 1.2 & 1.6 & 1.3 & 1.6 & 1.4 & 1.4 & 1.4 & \\
\hline $\begin{array}{l}\text { Allergy/allergic reaction NOS } \\
\text { A92 }\end{array}$ & 1.9 & 1.0 & 1.0 & 2.1 & 2.0 & 0.5 & 1.4 & \\
\hline Trauma/injury NOS A80 & 2.7 & 0.3 & 0.8 & 2.7 & 1.1 & 1.9 & 1.4 & \\
\hline General disease NOS A99 & 1.5 & 1.0 & 1.0 & 1.6 & 0.8 & 1.9 & 1.2 & \\
\hline R:respiratory & 17.8 & 13.6 & 15.6 & 15.4 & 12.7 & 20.1 & 15.5 & no significant difference \\
\hline $\begin{array}{l}\text { Upper respiratory infection } \\
\text { acute } \mathrm{R} 74\end{array}$ & 8.9 & 4.2 & 6.8 & 5.4 & 4.5 & 9.3 & 6.4 & \\
\hline Tonsilitis acute R76 & 3.3 & 2.3 & 2.6 & 3.2 & 2.5 & 3.3 & 2.8 & \\
\hline Cough R05 & 1.5 & 1.9 & 2.1 & 1.6 & 1.1 & 2.8 & 1.8 & \\
\hline $\begin{array}{l}\text { Sneezing/nasal congestion } \\
\text { R07 }\end{array}$ & 0.8 & 2.3 & 2.7 & 1.0 & 1.4 & 1.9 & 1.6 & \\
\hline L:musculoskeletal & 14.3 & 10.1 & 12.4 & 11.5 & 9.6 & 15.9 & 12.0 & no significant difference \\
\hline Sprain/strain of ankle L77 & 3.1 & 1.3 & 2.6 & 1.1 & 2.0 & 2.3 & 2.1 & \\
\hline $\begin{array}{l}\text { Back symptom/complaint } \\
\text { L02 }\end{array}$ & 2.3 & 1.3 & 2.4 & 0.5 & 1.7 & 1.9 & 1.8 & \\
\hline $\begin{array}{l}\text { Knee symptom/complaint } \\
\text { L15 }\end{array}$ & 0.8 & 1.9 & 1.3 & 1.6 & 2.0 & 0.5 & 1.4 & \\
\hline $\begin{array}{l}\text { Hand/finger symptom } \\
\text { complaint L12 }\end{array}$ & 0.8 & 1.6 & 1.3 & 1.1 & 0.6 & 2.3 & 1.2 & \\
\hline $\begin{array}{l}\text { Foot/toe symptom } \\
\text { complaint L17 }\end{array}$ & 1.9 & 0.3 & 1.3 & 0.5 & 0.3 & 2.3 & 1.1 & \\
\hline $\begin{array}{l}\text { Sprain/strain of joint NOS } \\
\text { L79 }\end{array}$ & 0.8 & 1.3 & 1.0 & 1.1 & 0.8 & 1.4 & 1.1 & \\
\hline S:skin & 8.1 & 6.8 & 7.8 & 6.9 & 4.5 & 12.2 & 7.4 & $\begin{array}{l}\text { significantly less frequent in } \\
\text { urban compared to } \\
\text { non-urban locations }\end{array}$ \\
\hline Acne 596 & 3.5 & 1.0 & 3.2 & 0.0 & 1.4 & 3.3 & 2.1 & \\
\hline $\begin{array}{l}\text { Skin symptom/complaint } \\
\text { other S29 }\end{array}$ & 1.5 & 1.6 & 1.3 & 2.1 & 0.8 & 2.8 & 1.6 & \\
\hline Warts S03 & 0.8 & 1.0 & 1.3 & 0.0 & 0.6 & 1.4 & 0.9 & \\
\hline P:psychological & 4.3 & 8.8 & 6.2 & 7.3 & 8.9 & 3.3 & 6.7 & $\begin{array}{l}\text { significantly more frequent } \\
\text { in urban compared to } \\
\text { non-urban locations }{ }^{c}\end{array}$ \\
\hline \multirow[t]{2}{*}{ Feeling depressed P03 } & 1.5 & 3.9 & 2.1 & 4.3 & 3.7 & 1.4 & 2.8 & \\
\hline & 0.0 & 2.3 & 1.6 & 0.5 & 2.0 & 0.0 & 1.2 & \\
\hline
\end{tabular}


Table 2 ICPC-2 coded main categories of reasons for consulting as indicated by young people before their consultation and most frequent subcategories (total frequency $>3$ ), by gender, by age-group and by practice location (numbers are percentages) (Continued)

\begin{tabular}{|c|c|c|c|c|c|c|c|c|}
\hline \multicolumn{9}{|l|}{$\begin{array}{l}\text { Anorexia nervosa/bulimia } \\
\text { P86 }\end{array}$} \\
\hline $\begin{array}{l}\text { Feeling anxious/nervous/ } \\
\text { tense P01 }\end{array}$ & 1.2 & 1.0 & 0.8 & 1.6 & 1.4 & 0.5 & 1.1 & \\
\hline Depressive disorder P76 & 0.4 & 1.0 & 0.5 & 1.1 & 0.8 & 0.5 & 0.7 & \\
\hline D:digestive & 2.7 & 5.2 & 3.3 & 5.0 & 5.9 & 0.9 & 4.1 & $\begin{array}{l}\text { significantly more frequent } \\
\text { in urban compared to } \\
\text { non-urban locations }^{d}\end{array}$ \\
\hline $\begin{array}{l}\text { Abdominal pain/cramps } \\
\text { general D01 }\end{array}$ & 0.0 & 1.9 & 0.8 & 1.1 & 1.4 & 0.0 & 1.1 & \\
\hline $\begin{array}{l}\text { Digestive symptom/ } \\
\text { complaint other D29 }\end{array}$ & 1.5 & 0.6 & 0.8 & 1.6 & 1.4 & 0.5 & 1.1 & \\
\hline Heartburn D03 & 0.0 & 1.3 & 0.5 & 1.1 & 1.1 & 0.0 & 0.9 & \\
\hline B:blood & 0.5 & 4.5 & 2.9 & 2.3 & 2.5 & 2.8 & 2.7 & $\begin{array}{l}\text { significantly more frequent in } \\
\text { females compared to males }\end{array}$ \\
\hline $\begin{array}{l}\text { Aneamia other/unspecified } \\
\text { B82 }\end{array}$ & 0.0 & 1.9 & 1.3 & 0.5 & 1.4 & 0.5 & 1.1 & \\
\hline $\begin{array}{l}\text { Iron deficiency anaemia B80 } \\
\text { (or blood test for iron, B34) }\end{array}$ & 0.0 & 1.3 & 0.8 & 0.5 & 0.6 & 0.9 & 0.7 & \\
\hline $\begin{array}{l}\text { T: metabolism, } \\
\text { endocrinology }\end{array}$ & 1.9 & 1.9 & 1.6 & 2.3 & 2.3 & 1.4 & 1.9 & no significant difference \\
\hline $\begin{array}{l}\text { Endocrine/met/sympt/ } \\
\text { complt other T29 }\end{array}$ & 1.2 & 0.6 & 0.3 & 2.1 & 1.1 & 0.5 & 0.9 & \\
\hline N:neurological & 1.9 & 1.6 & 2.3 & 1.2 & 2.3 & 0.9 & 1.8 & no significant difference \\
\hline Headache N01 & 1.2 & 1.0 & 1.0 & 1.1 & 1.4 & 0.5 & 1.1 & \\
\hline Z: Social problems & 1.5 & 0.3 & 1.3 & 0.0 & 1.1 & 0.5 & 0.9 & no significant difference \\
\hline Social problems NOS Z29 & 1.2 & 0.3 & 1.0 & 0.0 & 0.8 & 0.5 & 0.7 & \\
\hline
\end{tabular}

Logistic regression adjusted for age-group, gender, urban location and clustering within practices

${ }^{\mathrm{b}} \mathrm{OR}=0.35 ; 95 \% \mathrm{Cl}=0.12-0.98 ; \mathrm{p}=0.047$

${ }^{\mathrm{c}} \mathrm{OR}=2.7 ; 95 \% \mathrm{Cl}=1.3-5.5 ; \mathrm{p}=0.007$

${ }^{\mathrm{d}} \mathrm{OR}=6.5 ; 95 \% \mathrm{Cl}=1.5-28.0 ; \mathrm{p}=0.013$

${ }^{\mathrm{e}} \mathrm{OR}=13.4 ; 95 \% \mathrm{Cl}=1.6-114.1 ; \mathrm{p}=0.019$

gynecological reasons for encounter in our study (as in the Franco-Belgian study). In the Australian study gynecological reasons for encounters were among the most frequent reasons for encounter for girls suggesting differences in health care systems and the role of family doctors.

Substance use was hardly mentioned by young people themselves despite the fact that many of them were excessive users of cannabis, alcohol or tobacco. [15] Young people might not see these as a medical problem or might not want to raise the topic. Substance use was also a rare reason for encounter in previous studies.

Interestingly, ten years ago in a study of health professionals' adolescent health training needs in Switzerland, the need for more training opportunities in management of complex situations (mental health, functional disorders in particular) stood out as an important need [5] Our current findings add to this by indicating the need to appropriately train family doctors to deal with common complaints such as respiratory and musculoskeletal complaints in adolescents as well as with vague complaints such as dizziness and unspecific pain for example. Postgraduate training and continuous medical education in adolescent health for family doctors should include a strong focus on adolescent preventive care, mental health and effective communication skills.

\section{Strengths and limitations}

ICPC coding was used based on the patients' words and not the doctors' interpretation of patient words as is often the case. Data was collected in a confidential context among consecutive patients consulting a primary care practitioner. ICPC coding was done rigorously with an experienced coder checking all codes. 
Table 3 Top Ten Reasons for encounter by gender and location of practice

\begin{tabular}{|c|c|c|c|c|c|c|}
\hline \multicolumn{7}{|c|}{ Top ten reasons for encounter } \\
\hline & Males & Females & \multicolumn{2}{|l|}{ Urban practices } & \multicolumn{2}{|l|}{ Non-urban practices } \\
\hline 1 & $\begin{array}{l}\text { Health maintenance/ } \\
\text { prevention }\end{array}$ & $\begin{array}{l}\text { Health maintenance/ } \\
\text { prevention }\end{array}$ & \multicolumn{2}{|c|}{ Health maintenance/prevention } & \multicolumn{2}{|c|}{ Health maintenance/prevention } \\
\hline 2 & $\begin{array}{l}\text { Upper respiratory } \\
\text { infection acute }\end{array}$ & $\begin{array}{l}\text { Preventive } \\
\text { immunisation/ } \\
\text { Medication }\end{array}$ & \multicolumn{2}{|c|}{ Preventive immunisation /Medication } & \multicolumn{2}{|c|}{ Upper respiratory infection acute } \\
\hline 3 & $\begin{array}{l}\text { Preventive } \\
\text { immunisation/ } \\
\text { Medication }\end{array}$ & $\begin{array}{l}\text { General symptom/ } \\
\text { complaint other }\end{array}$ & \multicolumn{2}{|c|}{ General symptom / complaint other } & \multicolumn{2}{|c|}{ Preventive immunisation /Medication } \\
\hline 4 & $\begin{array}{l}\text { General symptom/ } \\
\text { complaint other }\end{array}$ & $\begin{array}{l}\text { Upper respiratory } \\
\text { infection acute }\end{array}$ & \multicolumn{2}{|c|}{ Upper respiratory infection acute } & \multicolumn{2}{|c|}{ General symptom/complaint other } \\
\hline 5 & Acne & Feeling depressed & \multicolumn{2}{|l|}{ Feeling depressed } & \multicolumn{2}{|l|}{ Tonsilitis acute } \\
\hline 6 & Tonsilitis acute & $\begin{array}{l}\text { Weakness/tiredness } \\
\text { general }\end{array}$ & \multicolumn{2}{|l|}{ Tonsilitis acute } & \multicolumn{2}{|l|}{ Acne } \\
\hline 7 & Sprain/strain of ankle & Tonsilitis acute & \multicolumn{2}{|c|}{ Weakness/tiredness general } & \multicolumn{2}{|l|}{ Cough } \\
\hline 8 & Trauma/injury NOS & $\begin{array}{l}\text { Sneezing/nasal } \\
\text { congestion }\end{array}$ & Blood test & $\begin{array}{l}\text { Allergy/allergic } \\
\text { reaction NOS }\end{array}$ & $\begin{array}{l}\text { Skin symptom/ } \\
\text { complaint other }\end{array}$ & $\begin{array}{l}\text { Sprain/strain of } \\
\text { ankle }\end{array}$ \\
\hline 9 & $\begin{array}{l}\text { Back symptom/ } \\
\text { complaint }\end{array}$ & $\begin{array}{l}\text { Anorexia nervosa/ } \\
\text { bulimia }\end{array}$ & $\begin{array}{l}\text { Sprain/strain of } \\
\text { ankle_Knee symptom }\end{array}$ & $\begin{array}{l}\text { Anorexia nervosa/ } \\
\text { bulimia }\end{array}$ & $\begin{array}{l}\text { Hand/finger symptom } \\
\text { complaint }\end{array}$ & $\begin{array}{l}\text { Foot/toe symptom } \\
\text { complaint }\end{array}$ \\
\hline 10 & $\begin{array}{l}\text { Allergy/allergic reaction } \\
\text { NOS }\end{array}$ & Cough & & & & \\
\hline
\end{tabular}

Our study also had limitations. The sample of health professionals was not random, and involved family doctors with a special interest in research, in young people and in quality of care. Overall, in our study, family doctors were younger and often female compared to the population of family doctors in Switzerland. However, the sample was varied with representatives of different age groups and both genders, single, double or group practices, in rural or urban settings, as shown in Table 1. Our hypothesis is that often older doctors no longer take on new patients. Therefore adolescents and young adults who seek a new family doctor turn to younger doctors. Thus it is not surprising that this younger age-group is overrepresented in our sample of family doctors volunteering for a study on the health of young people attending primary care [22]. Reassuring is that data from the Swiss Sentinel Surveillance Network [23] show a gender balance of $47.6 \%$ of boys and $52.4 \%$ of girls in the 15 to 24 year old age group of patients consulting family doctors in Switzerland. The gender balance in our study population is very similar ( $47 \%$ boys and $53 \%$ girls).

Since all consecutive patients were included, selection bias at the patient level was also limited. As there was no data collection on reasons for refusals it is not possible to know if these patients suffered from more severe condition or substance abuse problems, yet the proportion of patients who declined participation was low. Another limitation was that young people could only state one reason for encounter and therefore some motives might have been missed. In the Franco-Belgian study the majority of patients stated only one reason for encounter, in the German study the mean number of reasons for encounter/patient was 1.5.

\section{Implication for practice and research}

Preventive care is an important part of the work of a family doctor but nowadays mainly focusing on the needs of aging population with complex chronic problems. Social workers and school professionals (nurse, psychologists, teachers,...) are crucial partners to develop effective interventions for young people, especially the most vulnerable ones [17]. Population based data and school health surveys show intentional and unintentional injuries as well as mental health issues to be the main burden of disease in young people in high income countries [4]. Recurrent pain (headache, stomachache or musculoskeletal) or vague complaints such as fatigue are often linked with mental health issues (anxiety, poor life satisfaction,..) [24].

The high frequency of general or preventive reasons for encounter as well as vague complaints or musculoskeletal reasons for encounter in our study as stated by young people themselves highlights the preventive role family doctors play in young people's health. These findings have to be integrated in pre and postgraduate training as well as in continuous education for medical doctors and other health professionals. Too often training sessions in relation to young people's health focus on sexual health or substance use and therefore 
do not respond to young people's or family doctors expressed needs.

Future work could compare, as done in the FrancoBelgian study, patient and health care providers' views using ICPC coded reasons for encounter, in order to assess the extent to which data from the medical file (such as those collected in the FIRE project) can similarly be used to assess patients' needs [9]. It could also be interesting to compare our results to reasons for encounter at different entry points such as emergency outpatient clinics which are known to attract more vulnerable populations with no regular source of care. Further research could also explore which topics are truly addressed during the medical encounter, regardless of the presenting reason. This could provide useful information as to the extent to which family doctors respond to the current health needs of adolescents and young adults during routine consultations.

\section{Conclusions}

Our findings provide useful guidance for family doctors training and health service planning in Europe. They underline the importance of research in private practices to improve health care and prevention in youth as well as linking population based and school health surveys data to clinical care research. Effective interventions to decrease burden of disease, especially mental health and substance use need to address environmental, family and individual factors .As for other age groups family doctors play a central role if effectively trained to address individual needs of patients as well as being able to collaborate in an active network.

\section{Abbreviations \\ ICPC-2: International Classification for Primary Care-2.}

\section{Competing interests}

The authors declare that they have no competing interests

\section{Authors' contributions}

AM contributed to the design of the protocol, analyzed the data and wrote the first draft of the manuscript. BB contributed to the design of the study protocol, and reviewing the manuscript. DL contributed to the interpretation of results and reviewing of the manuscript, FN contributed in designing the protocol, interpreting the results and reviewing the manuscript. DH designed the protocol, collected and analyzed the data, wrote the first draft of the manuscript. All authors read and approved the final manuscript.

\section{Acknowledgments}

Damien Fayolle medical student University of Geneva, the participants of PRISMAdo trial.

\section{Details of financial support}

The PRISM-Ado trial was supported by the Safra Foundation \& Geneva University Hospitals, Switzerland, the Käthe-Zingg-Schwichtenberg Fund (Swiss Academy for Medical Sciences) and the Swiss Federal Office of Public Health.

\section{Author details}

'Adolescent and young adult program, Department of Child and Adolescent Health, Geneva University Hospitals, 87 Bvd de la Cluse, 1205 Geneva, Switzerland. ${ }^{2}$ Dependencies unit, Division of primary care, Department of Community Medicine, Primary Care and Emergency, Geneva University
Hospitals, 4 rue Gabrielle-Perret-Gentil, 1211, Geneva 14, Switzerland. ${ }^{3}$ Private general practice 93 Route de Suisse, 1290 Versoix, Switzerland. ${ }^{4}$ Primary care research and teaching unit. Faculty of Medicine, University of Geneva CMU, 9 av de Champel, 1211, Geneva, Switzerland.

Received: 23 April 2015 Accepted: 16 October 2015

Published online: 30 October 2015

\section{References}

1. Resnick MD, Catalano RF, Sawyer SM, Viner R, Patton GC. Seizing the opportunities of adolescent health. Lancet. 2012;379(9826):1564-7.

2. Haller DM, Michaud PA, Suris JC, Jeannin A, Narring F. Opportunities for prevention in primary care in a country with universal insurance coverage. J Adolesc Health. 2008;43(5):517-9.

3. Meynard A, Haller DM . Rôle du médecin de famille dans la promotion de la santé des adolescents: «Life course approach». Primary Care. 2015;15(02):235.

4. Patton GC, Coffey C, Sawyer SM, Viner RM, Haller DM, Bose K, et al. Global patterns of mortality in young people: a systematic analysis of population health data. Lancet. 2009;374(9693):881-92.

5. Gore FM, Bloem PJ, Patton GC, Ferguson J, Joseph V, Coffey C, et al . Global burden of disease in young people aged 10-24 years: a systematic analysis. Lancet. 2011;377(9783):2093-102.

6. Michaud PA, Ambresin AE. The health of adolescents in Switzerland. Praxis (Bern 1994). 2013;102(18):1111-6.

7. Sanci LA, Coffey CMM, Veit FCM, Carr-Gregg M, Patton GC, Bowes G, et al. Evaluation of the effectiveness of an educational intervention for general practitioners in adolescent health care: randomised controlled trial. BMJ. 2000;320(7229):224-30

8. Kraus B, Stronski S, Michaud PA. Training needs in adolescent medicine of practising doctors: a Swiss national survey of six disciplines. Med Educ. 2003:37(8):709-14.

9. Chmiel C, Bhend H, Senn O, Zoller M, Rosemann T. The FIRE project: a milestone for research in primary care in Switzerland. Swiss Med Wkly. 2011;140:w13142.

10. Busato A, Bhend H, Chmiel C, Tandjung R, Senn O, Zoller M, et al. Improving the quality of morbidity indicators in electronic health records in Swiss primary care. Swiss Med Wkly. 2012;142:w13611.

11. Rizza A, Kaplan V, Senn O, Rosemann T, Bhend H Tandjung R. Age- and gender-related prevalence of multimorbidity in primary care: the Swiss FIRE project. BMC Fam Pract. 2012;13:113.

12. Haller DM, Sanci LA, Patton GC, Sawyer S. Toward youth friendly services: a survey of young people in primary care. J Gen Intern Med. 2007;22(6):77581.

13. Frese T, Klauss S, Herrmann K, Sandholzer H . Children and adolescents as patients in general practice - the reasons for encounter. J Clin Med Res. 2011;3(4):177-82

14. Paulus $\mathrm{D}$, Pestiaux D, Doumenc $M$. Teenagers and their family practitioner: matching between their reasons for encounter. Fam Pract. 2004;21 (2):143-5.

15. Haller DM, Meynard A, Lefebvre D, Ukoumunne OC,Narring F, Broers B. Effectiveness of training family physicians to deliver a brief intervention to address excessive substance use among young patients: a cluster randomized controlled trial. CMAJ. 2014;186(8):E263-72.

16. Swiss Health Observatory. Health system, outpatient care. 2015 Accessed September 2015; Available from: http://www.obsan.admin.ch/fr/themes-desante/secteur-ambulatoire.

17. Jeannin A, Narring F, Tschumper AM, Inderwildi Bonivento L, Addor V, Bütikofer A, et al. Self-reported health needs and use of primary health care services by adolescents enrolled in post-mandatory schools or vocational training programmes in Switzerland. Swiss Med Wkly. 2005;135(1-2):11-8.

18. Sawyer SM, Afifi RA, Bearinger LH, Blakemore SJ, Dick B, Ezeh AC, et al Adolescence: a foundation for future health. Lancet. 2012;379(9826):163040.

19. Sanci LA, Sawyer SM, Weller PJ, Bond LM, Patton GC. Youth health research ethics: time for a mature-minor clause? Med J Aust. 2004;180(7):336-8.

20. Loi fédérale relative à la recherche sur l'être humain. 2014 Accessed October 2015; Available from: https://www.admin.ch/opc/fr/classified-compilation/ 20061313/index.html.

21. Haller DM, Sebo P, Cerrutti B, Bertrand B, Eytan A, Niveau G, et al. Primary care services provided to adolescents in detention: a cross-sectional study using ICPC-2. Acta Paediatr. 2010;99(7):1060-4. 
22. The Commonwealth fund:Commonwealth Fund International Survey of Primary Care Doctors 2012 Accessed September 2015; Available from: http://www.commonwealthfund.org/publications/surveys/2012/nov/2012international-survey.

23. The Swiss Sentinel Surveillance Network:Swiss Federal Office of Public Health, Division of Epidemiology and Infectious Diseases. 2013 Accessed September 2015; Available from: http://www.bag.admin.ch/ k_m_meldesystem/00736/00817/index.html?lang=fr.

24. Meynard A, Narring F. Adolescents with chronic pain: practical assessment and management. Rev Med Suisse. 2014;10(434):1287-91.

\section{Submit your next manuscript to BioMed Central} and take full advantage of:

- Convenient online submission

- Thorough peer review

- No space constraints or color figure charges

- Immediate publication on acceptance

- Inclusion in PubMed, CAS, Scopus and Google Scholar

- Research which is freely available for redistribution 